\title{
FUNCTIONALITY OF A RHEOMETER-BIOREACTOR TO STRESS AND ENGINEER TISSUE AT SONIC FREQUENCIES
}

\author{
*Sarah A. Klemuk, Ph.D. ${ }^{\text {A }}$ \\ Ingo R. Titze, Ph.D. ${ }^{A, B}$
Department of Communication Sciences and Disorders ${ }^{A}$ The University of Iowa, Iowa City, IA \\ The National Center for Voice and Speech ${ }^{B}$ \\ University of Utah, Salt Lake City, UT
}

\section{Introduction}

Millions of Americans suffer from hearing loss, voice problems or repetitive motion injuries. When tissues are set into vibration at sonic frequencies, the (complex) shear modulus largely governs their macroscopic vibrational properties. Conditioning engineered tissues at sonic physiologic vibrations is believed to improve their functionality when transplanted into patients. Instruments called bioreactors, uniquely designed for the purpose of growing tissues, exposing the tissue to vibration, and quanitfyint their mechanical response, are needed to investigate the potential public health benefits of such treatment. Primary functionalities of a bioreactor include (1) establishing uniform cell distributions in 3D constructs, (2) maintaining gas and nutrient concentrations, (3) providing fluid circulation, and (4) exposing developing tissue to physical stimuli.(Freed and Vunjak-Novakovic, 2000) A stress-controlled rheometer was adapted to function as a bioreactor. The degree to which the rheometer-bioreactor could satisfy the four criteria and simulate vocalization forces were evaluated.

\section{Methods}

The Gemini rotational shear rheometer (Malvern Instruments, UK) was used. Appliance adaptations were used to accommodate a 3D matrix and a monolayer of cells. For both adaptations, a custom cup, capable of being sterilized and holding cell culture medium, was fitted to the rheometer base. For the 3D configurations, a polyurethane substrate, used in other bioreactor experiments,(Titze and others, 2004) was seeded with fibroblast cells. The cells were incubated in static conditions for two weeks, and then exposed to vibrations in the rheometer bioreactor. Cell viability was quantified and compared to control conditions, applied torque and resulting strains were recorded, along with linear viscoelastic measurements of the 3D construct for three different vibration conditions. A similar experiment was performed using a dermal equivalent 3D matrix cell culture medium. For the monolayer configuration, cells were seeded onto a coverslip. The coverslip was then attached to either the stationary base or the top rotating plate. Vibration was exerted in the bioreactor by immersing the coverslip in cell culture medium augmented with methyl cellulose to increase fluid viscosity.Stresses up to 4000 $\mathrm{Pa}$ at $100 \mathrm{~Hz}$ were turned on and off every $10 \mathrm{~s}$ for $2 \mathrm{~h}$. 


\section{Results}

Fibroblast-seeded discs maintained comparable cell viability to controls, whether in static or vibrational conditions. Resulting strains was quantified throughout testing, and rheologic data were obtained.(Klemuk, Jaiswal, and Titze, 2008) Highly cellularized $100 \mu \mathrm{m}$ thick dermal membranes were unaffected by $10 \mathrm{~Hz}$ vibration but were morphologically changed after 1 hour exposure to $100 \mathrm{~Hz}, 60 \%$ strain vibration. A monolayer of laryngeal fibroblast cells, subjected to 2 hours of vibraton, remained unchanged for stress exposures up to $3000 \mathrm{~Pa}$ and $100 \mathrm{~Hz}$, but with higher forces, the cells were stripped or adversely deformed.

\section{Discussion}

These results demonstrate observable tissue response to phonation-like forces in the rheometer-bioreactor at the cellular level and at the macroscopic properties level, even when exposure time is limited. By modifying cup and plate attachments, tissue constructs of varying architectures can be studied. Modifications to the rheometerbioreactor are ongoing to increase testing duration and extend vibration conditions.

\section{References}

1. Freed, L. E. and Vunjak-Novakovic, G. (2000). Tissue Engineering Bioreactors, in Lanza R.P., Langer R., and Vacanti, J., editors, Principles of Tissue Engineering: San Diego, Academic Press, p. 143-156.

2. Klemuk, S. A., Jaiswal, S., and Titze, I. R. (2008). Cell viability viscoelastic measurement in a rheometer used to stress and engineer tissues at low sonic frequencies: Journal of the Acoustical Society of America, v. 124, p. 2330-2339.

3. Titze, I. R., Hitchcock, R. W., Broadhead, K., Webb, K., Li, W., Gray, S. D., and Tresco, P. A. (2004). Design and validation of a bioreactor for engineering vocal fold tissues under combined tensile and vibrational stresses: Journal of Biomechanics, v. 37, p. 1521-1529. 